\title{
Economic burden of environmental tobacco smoke on Hong Kong families: scale and impact
}

\author{
J Peters, C J McCabe, A J Hedley, T H Lam, C M Wong
}

\begin{abstract}
Study objective-To examine the financial cost of doctor consultations for cough, phlegm, and wheeze in children living in a home where family members smoke compared with those not exposed to environmental tobacco smoke. To model these costs to provide the Territory of Hong Kong with estimates of potentially avoidable health care resource use.
\end{abstract}

Design-Cross sectional questionnaire survey.

Subjects and setting-All children (10 615) in classes primary 3 to 6 (aged 8-13 years) attending 27 schools in two districts of Hong Kong in 1992 and their parents.

Measurements and main results-Doctor consultations during the previous three months for symptoms of either cough, phlegm or wheeze were higher in younger children, ranging from $22.9 \%$ in 8 year olds to $8.4 \%$ in those aged 12 or over. For those children living in homes with one, or more than one, smoker category (there were four categories of smokers: father, mother, siblings, others), the adjusted odds ratios ( $95 \%$ confidence intervals) for a doctor consultation for any of these symptoms were $1.15(1.01,1.31)$ and 1.38 $(1.14,1.67)$ respectively. Using US\$15 as the minimum cost incurred per consultation, the expected direct cost per annum per child of doctor consultations was $14 \%$ higher for children living in a one smoker category home and $25 \%$ for two or more compared with exposure to no smokers in the home. Using these values on a territory wide basis, the annual avoidable direct cost associated with exposure to tobacco smoke in children from birth to 12 years of age ranged from US\$338 042 to US\$991 591.

ScHARR, The

University of Sheffield, Sheffield

J Peters

C J McCabe

Department of

Community Medicine,

The University of

Hong Kong, Hong

Kong

A J Hedley

T H Lam

C M Wong

Correspondence to: Dr J Peters, ScHARR, Regent Court, 30 Regent Street, Sheffield S1 4DA.

Accepted for publication 7 March 1997 shown a relation for young children between hospitalisation for respiratory illness or asthma and exposure to ETS. ${ }^{2-6}$ The action of hospitalisation, however, is effectively a response at the tip of the respiratory illness iceberg. Below this are those who use community health care in the form of a doctor consultation for their respiratory complaints. Two recent studies have examined doctor consultation rates and exposure to $\mathrm{ETS}^{78}$ with conflicting results. van Reek and Adriaanse demonstrated a significant trend in visits to a general practitioner in 15 year old Dutch children over a six month period after exposure to one, or two or more smokers, although the reason for the doctor consultation was not stated. ${ }^{7}$ In contrast with this, Bruusgaard et al found no association between family smoking and the use of general practitioner services for respiratory tract infection ( $72 \%$ of all contacts), in Norwegian children aged $0-4$ years. $^{8}$

In a study of the respiratory health of primary school children in Hong Kong the impact of exposure to ETS in the family home on the frequency of doctor consultations for cough, phlegm, and wheeze was examined in two urban communities. An association between exposure to ETS and excess risks for cough, phlegm, sore throat, nasal symptoms, and wheeze has been shown in these children. ${ }^{910}$ This paper considers the costs associated with the excess risk for respiratory symptoms associated with exposure to ETS.

The traditional taxonomy of cost used in evaluations of health care interventions identifies three separate categories of cost: direct, indirect, and intangible. ${ }^{11}$ Both direct and indirect costs can be expressed in financial terms, while intangible costs cannot. Direct costs are those financial costs that are incurred as a direct effect of the treatment, this includes the costs borne by the health sector to provide the intervention and costs incurred by the patients and their families, for example, baby-sitting services while the parent takes the sick child to the doctor. ${ }^{12}$ Indirect costs are those financial costs that are borne by the patient, their families and society in relation to the intervention but not as a direct result of the intervention, for example, production losses. Intangible costs are those costs for which no financial value is readily available, for example, pain, anxiety. They may be necessary for the patient to receive the intervention or they may be only related to the intervention. While intangible costs are clearly a cost, to the extent that they impact negatively on an individual's utility, their financial value can only be calculated with difficulty and therefore is not incorporated into 
a cost-benefit equation. We have calculated only the direct costs of exposure to ETS, no indirect or intangible costs are included. Hence, to the extent that childhood illness represents a welfare loss to the parents and family of the affected children the reported costs are an underestimate of the true cost of exposure to ETS.

\section{Methods}

SUBJECTS AND SETTING

Chinese primary schoolchildren aged 8 to 13 years attending one of 27 schools in two districts of Hong Kong were enrolled, with their parents, in a two phase respiratory health and air pollution study from 1989 to 1992 . The initial selection of the original 17 schools, children, and details of the study design have been reported elsewhere..$^{1013}$ The principal criterion for selection in one district was that the schools were located in areas with poor air quality, as rated by local Government officials and the Government Environmental Protection Department. In the second district, because of its better air quality overall, all schools were located in areas of low air pollution. In the second phase of the study, in 1991-1992, an additional 10 schools were recruited. These were equally distributed between the two districts and situated in close proximity to schools already participating in the study.

\section{STUDY INSTRUMENT}

Two questionnaires, one for parents, and a second for children, were developed from, and based on, internationally validated questionnaires. ${ }^{14}{ }^{15}$ Some of the questions were included on both the parents' and children's questionnaires for validation purposes. Questionnaires were completed in the classroom under the supervision of a trained researcher and with no teachers present during the period from the end of March through to June. Parents' questionnaires were sent home and returned to school in sealed envelopes, upon completion.

DATA

Respiratory symptoms

Questions on respiratory symptoms experienced by the child included: symptoms of cough in the morning, cough in the evening, cough in the last three months, phlegm in the morning, phlegm day and night, phlegm in the last three months, sore throat, nasal symptoms, and wheeze. Questions were asked of both the parents and the children. The children's responses were used.

\section{Doctor consultations}

The child was asked whether they had consulted a doctor in the last three months specifically for individual symptoms of cough, phlegm, or wheeze. An aggregated "any symptom" variable was computed from positive responses to consultations for any one of the three symptoms.
KEY POINTS

- Additional doctor consultations for specific respiratory symptoms are made by children who live in a home with smokers compared with those who do not.

- The expected direct costs of consultation are $13 \%$ higher for those living with one smoker and $25 \%$ higher for those living with two or more smokers, compared with those living in a non-smoking home.

- For the Hong Kong population 0-12 years, the annual avoidable direct cost has been estimated as US\$338000 to US\$992 000 .

\section{Smoking practice}

Information was collected, on both the children's and parents' questionnaires, on the current smoking practice of family members and others living in the family home. The responses used for the analysis were taken from the children's answers. Exposure to smoking in the home was coded into three smoker categories (none, one, two or more) from positive responses to questions asking if the mother, father, siblings at home, or others living in the family home, smoked. The children were asked to describe their own smoking experience from the following options: never, tried a few times, used to but not now, smoke less than one cigarette per week, smoke 1-6 cigarettes per week, smoke more than six cigarettes per week. The answers were dichotomised into never and ever-child smokers.

\section{Socioeconomic factors}

Socioeconomic status was assessed from questions on the parents' questionnaire on the size (open question) and type of housing (public, private self contained, private shared, home ownership, temporary, others), their educational attainment (no formal education, primary, lower secondary, upper secondary, tertiary), occupational status (none/housewife, professional, clerical, sales, services, manufacturing, other), and current occupation (currently employed or not).

\section{STATISTICAL ANALYSIS}

Frequency distributions were constructed for doctor consultations for each symptom. Logistic regression models were developed with smoking in the home used as a predictor for doctor consultation for each symptom; cough, phlegm, wheeze, and for any symptom, with adjustment made for potential confounders, as follows: age (in years, as a continuous variable), sex, district of residence (district with a low level of air pollution compared with that with a higher level), father's education level (primary, lower secondary, upper secondary and post secondary all compared with no formal education), and type of housing (all other compared with public). These potential confounders were selected on the basis of the literature and results from univariate analyses and all were included in each model. Adjusted odds ratios 
Table 1 Prevalence of doctor consultations for symptoms by age, sex, and household smoking category

\begin{tabular}{|c|c|c|c|c|c|}
\hline & \multirow{2}{*}{$\begin{array}{l}\text { Number of } \\
\text { children }\end{array}$} & \multicolumn{4}{|c|}{ Doctor consultation (\%) for } \\
\hline & & Cough & Phlegm & Wheeze & Any symptom \\
\hline \multicolumn{6}{|l|}{ Age (y) } \\
\hline 8 & 1522 & 20.0 & 9.4 & 3.1 & 22.9 \\
\hline 9 & 2702 & 15.1 & 6.1 & 2.9 & 17.8 \\
\hline 10 & 2850 & 12.8 & 4.9 & 2.2 & 15.2 \\
\hline 11 & 2316 & 11.2 & 4.1 & 2.1 & 13.2 \\
\hline $12+$ & 1225 & 7.2 & 2.4 & 1.9 & 8.4 \\
\hline \multicolumn{6}{|l|}{ Sex } \\
\hline Boys & 5360 & 13.4 & 5.4 & 3.2 & 16.1 \\
\hline Girls & 5255 & 13.4 & 5.3 & 1.7 & 15.4 \\
\hline \multicolumn{6}{|c|}{ Household smoking category } \\
\hline None & 5664 & 12.5 & 4.7 & 2.2 & 14.6 \\
\hline One & 3748 & 14.3 & 6.0 & 2.4 & 16.6 \\
\hline Two or more & 1203 & 15.0 & 6.5 & 3.6 & 18.2 \\
\hline
\end{tabular}

with their 95\% confidence intervals were calculated.

ECONOMIC COSTS

The average price charged by a private general practitioner in Hong Kong has been calculated to be US $\$ 15 .{ }^{16}$ Sixty five per cent of all patients use a private practice. ${ }^{16}$ On this basis, US $\$ 15$ is assumed to be the direct cost of provision of a doctor consultation in this paper. The question completed by the child did not differentiate between one or multiple visits for a given symptom, and one visit only has been assumed. A second and significant source of direct cost is the cost of adult supervision for the child to and from the consultation. Given the overall high level of employment in Hong Kong at $97.5 \%{ }^{17}$ and the reported figures of $94 \%$ and $46 \%$ for current employment of fathers and mothers of the children in this study ${ }^{9}$ it is assumed that adult supervision requires absence from work. The cost of this absence has been calculated on the basis of the median wage rate in Hong Kong and is valued at US $\$ 14$ for half a day (1991 figures). ${ }^{18} \mathrm{~A}$ further US $\$ 15$ has been allowed to cover travel expenses and other sundry expenses, (such as self medication with over the counter preparations (including herbal medicine), special meals for children and adult refreshments, purchasing of toys and sweets as incentives for children to see a doctor and take prescribed medicines), incurred by the child and the adult as part of the consultation package. ${ }^{19}$ This gives an estimated total direct cost for a child's consultation with a general practitioner in Hong Kong of US $\$ 44$.

The total costs of ETS are presented as: cost of doctor consultations for any symptom only; cost of doctor consultations with adult supervision; and cost of doctor consultations with adult supervision and associated expenses. The full set of results is presented using calculations based upon the doctor consultation cost only. Total avoidable cost and avoidable cost by smoker category are calculated on the basis of doctor consultation cost only, and total direct costs.

The total direct cost of doctor consultations for children in households in each smoker category (no smokers in the home, one smoker category, two or more smoker categories) was calculated by multiplying the cost of a doctor consultation by the number of consultations in each category. The expected cost per child for doctor consultations in each ETS exposure category was calculated by dividing the total direct cost by the number of children in each category. Using these expected costs, it is possible to calculate the avoidable expenditure (or excess cost) associated with exposure to one and two or more smoker categories in the home compared with none. To the extent that children may have attended a doctor on more than one occasion during the three month period studied, the cost estimates represent a lower bound for the true total cost. Estimates of the burden for the whole territory were calculated in two stages. The first stage assumed that the exposure and relative risk observed in the sample were generalisable to the whole Hong Kong population aged between 8 and 12 years. The second stage assumed that the exposure and relative risk observed in the sample were also generalisable to the whole population aged 7 years or under.

All analyses were carried out using SPSS 4.1 PC and Microsoft Excel 5.0.

\section{Results}

RESPONSE RATES

In 1992,10615 children took part in the study. Response rates for the questionnaires were $98 \%$ and $95 \%$ for children and parents respectively. The individual question answers were $80 \%$ or more complete in the parent's questionnaires and for the children, each question had less than $1 \%$ of missing answers. There were no differences in these rates between schools.

\section{RESPIRATORY SYMPTOMS AND DOCTOR}

CONSULTATIONS

Consultation rates for all symptoms were highest in the youngest age groups and declined with age (table 1). Overall, 13.4\% (1426) of children had made at least one doctor consultation in the last three months for symptoms of cough, $5.4 \%$ (570) for phlegm, $2.4 \%$ (260) for wheeze, and $15.7 \%$ for any symptom. No significant differences in consultation rates were found between boys and girls (for cough: $\chi^{2}=0.01, \mathrm{p}=0.97$; for phlegm: $\chi^{2}=0.01$, $\mathrm{p}=0.94$, for wheeze: $\chi^{2}=0.68, \mathrm{p}=0.41$ ) (table 1 ), and none between those living in the air polluted district and in the district with cleaner air (for cough: $\chi^{2}=0.83, p=0.36$; for phlegm, $\chi^{2}$ $=1.97, \mathrm{p}=0.16$, for wheeze: $\left.\chi^{2}=004, \mathrm{p}=0.84\right)$.

\section{EXPOSURE TO TOBACCO SMOKE}

Thirty six per cent (3748) of children lived in homes with one smoker category and $11.3 \%$ (1203) with two or more. Table 1 gives the doctor consultation rates for symptoms of cough, phlegm, wheeze, and any symptom by exposure to none, one, or two or more smoker categories. Overall, an additional $2.4 \%$ doctor consultations were made for any symptom by those children living in a smoking home compared with those living in a non-smoking household.

Eleven per cent (1141) of children claimed to be ever smokers and these were excluded 
Table 2 Doctor consultations for respiratory symptoms by household smoking category, age, sex, and housing type (adjusted odds ratios (OR) and 95\% confidence intervals (CI))

\begin{tabular}{|c|c|c|c|c|}
\hline & \multicolumn{4}{|c|}{ Doctor consultation for } \\
\hline & $\begin{array}{l}\text { Cough } \\
\text { Adj OR }(95 \% \text { CI) }\end{array}$ & $\begin{array}{l}\text { Phlegm } \\
\text { Adj OR (95\% CI) }\end{array}$ & $\begin{array}{l}\text { Wheeze } \\
\text { Adj OR (95\% CI) }\end{array}$ & $\begin{array}{l}\text { Any symptoms } \\
\text { Adj OR }(95 \% \text { CI) }\end{array}$ \\
\hline \multicolumn{5}{|l|}{ Household smoking category } \\
\hline None & 1 & 1 & 1 & 1 \\
\hline One & $1.15(1.01,1.32)$ & $1.26(1.02,1.54)$ & $1.04(0.76,1.41)$ & $1.15(1.01,1.31)$ \\
\hline Two or more & $1.33(1.08,1.64)$ & $1.33(0.97,1.83)$ & $1.57(1.02,2.43)$ & $1.38(1.14,1.67)$ \\
\hline \multicolumn{5}{|l|}{ Age } \\
\hline Increasing by year & $0.77(0.73,0.82)$ & $0.72(0.66,0.78)$ & $0.90(0.80,1.01)$ & $0.78(0.74,0.82)$ \\
\hline \multicolumn{5}{|l|}{ Sex } \\
\hline $\begin{array}{l}\text { Boys compared with girls } \\
\text { Housing }\end{array}$ & $1.03(0.91,1.17)$ & $1.02(0.84,1.23)$ & $1.79(1.34,2.38)$ & $1.38(1.14,1.67)$ \\
\hline Public compared with all other & $1.16(1.01,1.32)$ & $1.19(0.97,1.46)$ & $1.20(0.88,1.62)$ & $1.15(1.01,1.30)$ \\
\hline Test for trend by smoking category & $\mathrm{p}<0.01$ & $\mathrm{p}<0.05$ & Not significant & $\mathrm{p}<0.001$ \\
\hline
\end{tabular}

Other variables in the logistic model, results not shown: father's education level, district of residence.

from the regression model along with cases with missing data (although similar results have been obtained with inclusion of, and adjustment for, ever-smoking children in the model). The final modelled data set comprised 8727 cases.

\section{MODELLED RESULTS}

After adjustment for age, sex, district of residence, father's education level and type of housing, exposure to ETS remained significant in the logistic model. Adjusted odds ratios with their associated $95 \%$ confidence intervals are presented for each symptom and for any symptom by smoking exposure levels (table 2). A significant positive linear trend $(\mathrm{p}<0.05)$ was found for prevalence of doctor consultation for cough, phlegm, and any symptom with exposure to an increasing number of smokers. The only other factors found to be significantly associated $(p<0.05)$ with doctor consultations were increasing age, which was protective for all symptoms, being male and living in public housing both of which showed higher risks for: wheeze and cough, respectively.

COSTS OF CONSULTATION

The total cost of doctor consultations by children not exposed to tobacco smoke in the home $(n=5664)$ was US $\$ 12404$. The total cost of doctor consultations for children exposed to one smoker category in the home $(n=3748)$ was US $\$ 9333$ and for exposure to two or more smoker categories $(n=1203)$,

Table 3 Expected costs per child of doctor consultations, over a three month period, by household smoking category

\begin{tabular}{llll}
\hline & \multicolumn{2}{l}{ Costs in US\$ } \\
\cline { 2 - 4 } Household smoker category & Doctor & $\begin{array}{l}\text { Doctor and adult } \\
\text { supervision }\end{array}$ & $\begin{array}{l}\text { Doctor, adult supervision, } \\
\text { and travel }\end{array}$ \\
\hline None & 2.19 & 4.23 & 6.42 \\
One & 2.49 & 4.81 & 7.30 \\
Two or more & 2.73 & 5.28 & 8.01 \\
\hline
\end{tabular}

Table 4 Total avoidable expenditure, over a three month period, by household smoking category

\begin{tabular}{llcl}
\hline & \multicolumn{2}{l}{ Costs in US\$ (thousands) } \\
\cline { 2 - 4 } Household smoker category & Doctor & $\begin{array}{l}\text { Doctor and adult } \\
\text { supervision }\end{array}$ & $\begin{array}{l}\text { Doctor, adult supervision, } \\
\text { and travel }\end{array}$ \\
\hline One & 44 & 86 & 130 \\
Two or more & 25 & 49 & 75 \\
Total & 70 & 135 & 206 \\
\hline
\end{tabular}

US $\$ 3284$. The expected costs per child for a doctor consultation with adult supervision and travel are $\$ 6.42, \$ 7.30, \$ 8.01$ for exposure to no smokers in the home, one smoker category, two or more smoker categories, respectively (table 3). The expected costs are also given for consultation and consultation with adult supervision (table 3). Children exposed to one smoker category had an expected cost $13.1 \%$ higher than children not exposed to ETS in the home and for children exposed to two or more smoker categories the expected cost was $24.7 \%$ higher.

Hong Kong has 420263 children aged 8 and 12 years. ${ }^{18}$ Assuming that the study results are generalisable, 148389 of these children live in homes in the one smoker category and 47628 children with two or more. Table 4 gives the total avoidable expenditure by household smoker category. Assuming a constant consultation rate throughout the year, the lowest estimate of the avoidable direct cost for the cohort aged 8-12 years is US $\$ 280944$ per annum and the highest estimate US\$824 104 per annum. The population cohort aged 0 to 7 years comprises 570709 children..$^{18}$ If the assumption is made that the observed exposure levels and effects of such exposure in the 8-12 year old cohort holds true for the 0-7 year old age group, the annual avoidable direct cost of doctor consultations associated with exposure to tobacco smoke in the family home would be a minimum of US $\$ 338042$ and a maximum of US $\$ 991591$ for children aged 0-12 years living in the Territory.

\section{Discussion}

It is common for discussions on the cost of smoking to society to take into account the benefits that society receives from the existence of the tobacco industry; employment, dividends and tax revenue as well as focusing on the costs of treating adults with smoking related diseases. ${ }^{20}$ But the cost of treating diseases or ill health in children are an additional cost, which is often forgotten but which also needs to be included in the total cost-benefit equation. Although Bruusgaard et $a l^{8}$ found no relation between smoking in the family and use of general practitioner services in his small group of 183 children, this study, with its similar findings to those of van Reek and Adriaanse, ${ }^{7}$ has shown that there is a 
significant financial burden associated with respiratory health problems after exposure to ETS. Other possible factors such as air pollutant exposure, as measured by district of residence did not have a significant impact on the number of doctor consultations for these children.

There are a number of reasons to believe that the costs presented in this paper are a significant underestimate of the true cost. This study confirms the findings of Munro et $a l^{1}$ that there is a negative trend between increasing age and number of doctor consultations for upper respiratory tract infection or respiratory symptoms. In Munro's study the negative trend was found to be highest in the 1-4 year old Hong Kong children. ${ }^{21}$ This suggests that demand for medical services in age groups younger than those measured in this study may be even greater. Secondly, these costs are lower bound costs based on an assumed single consultation during a three month time period. It is possible that a proportion of those children who reported a doctor consultation for a given respiratory symptom consulted more than once during that period for similar symptoms. Munro et al reported that, for upper respiratory tract infection, 1-4 year old girls consulted three times per year and boys twice, ${ }^{21}$ although this is a conflicting finding to that of the greater vulnerability to respiratory illness seen in the boys in this study compared with the girls. ${ }^{9}{ }^{10}$ His older children consulted twice per year and older teenagers and adults once. ${ }^{21}$ Other evidence to support multiple consultations comes from the high incidence of "doctor shopping" practised by certain groups within the Hong Kong population. ${ }^{22}$ Consultations are often made with more than one doctor for the same problem thus multiplying the cost per health problem. Thirdly, only the costs to the family of the child's consultation have been included in our analysis. Neither the wide range of treatment costs, such as those for medication for such as Chinese medicine, which can be incurred after a consultation for cough, wheeze or phlegm nor allowance for value of "pain and suffering" have been incorporated into the analysis. The latter will include not only the child's physical pain caused by the respiratory symptoms but also any emotional and mental trauma such as that associated with missed schooling, stress of the consultation.

Although these costs have been calculated on the assumption that all consultations were with a private practitioner rather than the $65 \%$ estimated ${ }^{16}$ the costs of the alternative model (all consultations using public medical facilities) comprise at least $80 \%$ of the overall figures.

No attempt has been made to quantify the level of demand on general practitioner time, but the excess number of consultations at 41264 per annum, for Hong Kong children aged $0-12$ years, represent a requirement for an additional full time work equivalent of five general practitioners per year (based on a seven hour day and 10 minutes per consultation). While for Hong Kong, with primary care pro- vided mainly through private practice this provides more work opportunities for medical graduates, in a primary health care system such as that in the United Kingdom it would mean fixed resources being stretched even further for consultations for treatment of a potentially preventable health complaint. Thus there are significant opportunity costs associated with doctor consultations for these comparatively minor complaints especially as primary care services are usually provided on a first come first served basis and therefore people with a higher degree of morbidity do not receive priority. The additional doctor consultations attributable to ETS increase the average waiting time for all people seeking a consultation. The additional load on services may lead to additional morbidity among all people seeking health care. This is also an economic burden directly attributable to exposure to ETS.

Exposure to ETS causes respiratory health problems for the child, an economic burden upon the whole family, and excess demand on health resources, all of which are avoidable. While the impact of this demand on each individual general practitioner's work load may be small there are important policy issues in the field of health education. The public needs to be made more aware of the full costs to society from exposure to tobacco smoke. There is a requirement for more specific and effective health education targeted at family members who smoke, which not only emphasises the health impact of smoking for them and their family but also the economic implications associated with their smoking.

The authors wish to thank all the schools, teachers, parents and children for their cooperation and participation in the study.

Funding: the study received financial support from the Kwai Tsing District Board, Glaxo Hong Kong Limited, The Royal Hong Kong Jockey Club and the Mary Sun Medical Scholarship Fund (Hong Kong - Cambridge Link), and the Environmental Protection Department, Hong Kong Government.

Conflicts of interest: none.

1 Environmental Protection Agency. Respiratory health effects of passive smoking: lung cancer and other disorders. Washington DC: EPA Office of Research and Development, Office of Air and Radiation, Office of Environmental Assessment, 1992. EPA Publication no 600/6-90-006f.

2 Haarlap S, Davies AM. Infant admissions to hospital and maternal smoking. Lancet 1974;i:529-32.

3 Fergusson DM, Horwood LJ, Shannon FT, et al. Parental smoking and lower respiratory illness in the first three years of life. f Epidemiol Community Health 1981;35:180-4.

4 Chen Y, Li W, Yu S. Influence of passive smoking on admissions for respiratory illness in early childhood. BMF 1986; 293:303-6.

5 Chen Y, Li W, Yu S, Qian W. Chang-Ning Epidemiological study of children's health: I: Passive smoking and children's respiratory disease. Int 7 Epidemiol 1988;17:348-55.

6 Weitzman M, Gortmaker S, Walker DK, Sobol A. Maternal smoking and childhood asthma. Pediatrics 1990;85:505-11. 7 van Reek J, Adriaanse H. Passive smoking and visits to the general practitioner by schoolchildren. F Public Health Med 1993;15:368-9.

8 Bruusgaard D, Kise SAH, Nilsson D. Health service consumption and parent reported episodes of illness in children 0-3 years. Scand $\mathcal{F}$ Prim Health Care 1993;11:14750

9 Hedley AJ, Peters J, Lam TH, et al. Air pollution and respiratory health in primary school children in Hong Kong, 1989-1992. Report to the Environmental Protection Department, Hong Kong Government. Hong Kong: Kong, 1993: 330 .

10 Peters J, Hedley AJ, Wong CM, et al. Effects of an ambient air pollution intervention and environmental tobacco air pollution intervention and environmental tobacco Epidemiol 1996;25:821-8. 
11 Drummond MF, Stoddard GL, Torrance GW. Methods for the economic evaluation of health care programmes. Oxford: the economic evaluation of healt

12 Cullis JG, West PA. The economics of health: an introduction. Oxford: Martin Robertson, 1979: 171-3

13 Ong SG, Liu J, Wong CM, et al. Studies on the respiratory health of primary school children in urban communities of Hong Kong. Sci Total Environ 1991;106:121-35.

14 Medical Research Council. Questionnaire on respiratory symptoms. London: MRC, 1960.

15 Florey C du V, Leeder SR. Methods for cohort studies of chronic airflow limitation. Copenhagen: WHO, 1982. WHO Regional Publications, European Series No 12

16 Hedley AJ, Cheng KK, Pei GK, et al. Health problems, choices of care and patterns of utilisation in a wellpopulation telephone survey: surveys on health and medical care in Hong Kong. Hong Kong: Report to Health and Welfare Branch, Hong Kong Government, 1990.
17 Ho LS. Labour and Employment. In: Cheng YS, Kwong PCK, eds. The Other Hong Kong Report. Hong Kong: ChiUniversity Press, 1992: 197

18 Census and Statistics Department, Hong Kong 1991 Popuation Census. Hong Kong: Government Printer, 1991:2844.

19 Barron WF, Liu J, Lam TH, Wong CM, Peters J, Hedley A. Costs and benefits of air quality improvement in Hong Kong. Contemporary Economic Policy 1995;XIII:105-17.

20 Choi BCK, Nethercott JR. The economic impact of smoking in Canada. International fournal of Health Planning and Management 1998;3:197-205.

21 Munro C, Lewis J, Lam C, Cho SK. Consulting patterns for some common respiratory conditions presented to the GPU. Hong Kong Practitioner 1991;13:1513-30.

22 Lo A, Hedley AJ, Pei GK, et al. Doctor-shopping in Hong Kong: implications for quality of care. Int $\mathcal{f}$ Qual Health Care 1994;6:371-81. 